alveolar hemorrhage next to the bronchus. Fragments of necrotic fibrous connective tissue were encrusted with golden-brown pigment that showed a strong reaction for ferric iron (Perls's coloration and Prussian blue).

To avoid such effects, clinicians caring for elderly patients should make sure that tablets are taken while sitting. Acute respiratory symptoms and hemoptysis in elderly patients can be a result of tablet inhalation. If removal of the iron tablet is not possible, a thoracotomy with bronchotomy, segmental resection, or lobectomy is indicated. ${ }^{5}$ Anesthetists, bronchoscopists, and cardiothoracic surgeons must act together.
2. Godden DJ, Kerr KM, Watt SJ, Legge JS. Iron lung: bronchoscopic and pathological consequences of aspiration of ferrous sulphate. Thorax 1991;46:142-3.

3. Lamaze R, Tréchot $P$, Martinet $Y$. Bronchial necrosis and granuloma induced by the aspiration of a tablet of ferrous sulphate. Eur Respir J 1994;7:1710-1.

4. Mizuki M, Onizuka O, Aoki T, Tsuda T. A case of remarkable bronchial stenosis due to aspiration of delayed-release irontablet (in Japanese with English abstract). Nippon Kyobu Shikkan Gakkai Zasshi 1989;27:234-9.

5. Tarkka M, Anttila S, Sutinen S. Bronchial stenosis after aspiration of an iron tablet. Chest 1988;93:439-41.

\title{
COMPLICATIONS OF FEMORAL ARTERY CANNULATION FOR PERIOPERATIVE MONITORING IN CHILDREN
}

Keith C. Kocis, MD, MSc, ${ }^{a}$ Roger P. Vermilion, MD, ${ }^{b}$ Louise B. Callow, RN, MSN, ${ }^{c}$ Thomas J. Kulik, MD, Achi Ludomirsky, MD, ${ }^{\mathrm{b}}$ and Edward L. Bove, MD, ${ }^{\mathrm{c}}$ Baltimore, Md., and Ann Arbor, Mich.

Arterial monitoring is essential for the perioperative treatment of children undergoing repair of congenital cardiac defects. Peripheral arterial cannulation in small children can be difficult, and catheter-related complications are common. ${ }^{1}$ For these reasons, femoral arterial cannulation is frequently performed. According to clinical criteria, the incidence of femoral artery complications (ischemia, thrombosis, embolism, and infection) after cannulation in children is between $0.1 \%$ and $14 \%{ }^{2}$ Clinical criteria are known to be insensitive, however, in the diagnosis of femoral artery obstruction in children. ${ }^{3-5}$ Ultrasonography has been shown to be sensitive and specific for the diagnosis of femoral artery obstruction. By means of ultrasonography, we recently demonstrated a $33 \%$ incidence of femoral artery obstruction among infants after cardiac catheterization ${ }^{3}$ and a $26 \%$ prevalence among children undergoing transfemoral arterial balloon angioplasty or valvuloplasty. ${ }^{4}$ The purposes of this study were to prospectively determine the prevalence of and predictors for complications of femoral artery cannulation for perioperative monitoring in children.

From the Department of Anesthesiology and Critical Care Medicine, The Johns Hopkins Medical Institutions, Baltimore, ${ }^{a}$ and Departments of Pediatrics ${ }^{\mathrm{b}}$ and Surgery, ${ }^{\mathrm{c}}$ University of Michigan Medical Center, Ann Arbor, Mich.

Received for publication Jan. 22, 1996; accepted for publication Feb. 2, 1996.

J Thorac Cardiovasc Surg 1996;112:1399-1400

Copyright (C) 1996 by Mosby-Year Book, Inc.

$0022-5223 / 96 \$ 5.00+0 \quad \mathbf{1 2 / 5 4 / 7 2 5 6 4}$
Thirty consecutive children with a mean age of $19 \pm 7$ months (median 5.3 months, range 1 day to 13 years) were entered prospectively into this study after femoral artery cannulation for perioperative arterial monitoring. The children's mean weight was $9.5 \pm 2.4 \mathrm{~kg}$ (median $5.4 \mathrm{~kg}$ ). Ten patients underwent palliative operations (including hemi-Fontan or Fontan operations); 20 underwent corrective operations. In the operating room, the femoral artery was cannulated percutaneously in 24 patients and by cutdown in six patients with a 22 gauge 1.38 -inch polyurethane catheter (Arrow International, Inc., Reading, $\mathrm{Pa}$.). Heparinized fluid was infused through the catheters. The femoral arteries were cannulated for $6.9 \pm$ 1.5 days (median 4 days, range 0.5 to 35 days). Indications for catheter removal and catheter complications, as diagnosed by clinical criteria (ischemia, peripheral embolism, hemorrhage, infection, and other), were recorded. Both femoral arteries were evaluated with ultrasonography $3.5 \pm 0.4$ days (range 0 to 11 days) after catheter removal. Femoral artery obstruction was diagnosed according to previously described criteria. ${ }^{3}$ The demographic and clinical data (age, weight, height, diagnosis, type of operation [palliative or corrective], previous cardiac catheterization, previous femoral artery cannulation, insertion technique [percutaneous or surgical cutdown], and duration of arterial cannulation) were collected, combined with outcome measures (clinical complications and ultrasonographic results), and analyzed with univariate and multivariate logistic regression modeling techniques.

Clinically, two (7\%, 95\% confidence interval $0 \%$ to $16 \%$ ) femoral artery complications occurred (Table I, patients 1 and 2). By means of ultrasonography, six patients (20\%) 
Table I. Femoral artery complications

\begin{tabular}{ccccccccc}
\hline Patient & Age & $\begin{array}{c}\text { Weight } \\
(\mathrm{kg})\end{array}$ & Cardiac defect & Operation & $\begin{array}{c}\text { Previous cardiac } \\
\text { catheterization }\end{array}$ & $\begin{array}{c}\text { Percutaneous } \\
\text { insertion }\end{array}$ & $\begin{array}{c}\text { Cannulation } \\
\text { (days) }\end{array}$ & Complication \\
\hline 1 & 13 years & 60 & CoA & Repair & Yes & Yes & 0.5 & Ischemia \\
2 & 2 years & 11 & Single ventricle & Fontan & Yes & Yes & 5 & Hemorrhage \\
3 & 1 day & 3.1 & VSD, IAA & Repair & No & Yes & 2 & Complete obstruction* \\
4 & 6 days & 6.0 & AVSD & Repair & No & Yes & 3 & Complete obstruction* \\
5 & 9 days & 2.4 & VSD, CoA & Repair & Yes & Yes & 9 & Complete obstruction* \\
6 & $4 \mathrm{mos}$ & 4.3 & AVSD & Repair & Yes & Yes & 2 & Complete obstruction* \\
7 & $4 \mathrm{mos}$ & 5.6 & AVSD, TOF & Repair & Yes & No & 6 & Complete obstruction* \\
8 & $6 \mathrm{mos}$ & 3.5 & Single ventricle & Mod BTS & Yes & Yes & 2 & Complete obstruction* \\
9 & $8 \mathrm{mos}$ & 6.5 & Unbalanced AVSD & Hemi-Fontan & Yes & Yes & 31 & Partial obstruction* \\
\hline
\end{tabular}

COA, Coarctation of aorta; VSD, ventricular septal defect; $L A A$, interrupted aortic arch; $A V S D$, atrioventricular septal defect; TOF, tetralogy of Fallot; Mod $B T S$, modified Blalock-Taussig shunt.

*Diagnosed by ultrasonography.

were found to have complete obstruction of the cannulated femoral artery and one $(3 \%)$ was found to have partial obstruction (95\% confidence interval $8 \%$ to $38 \%$; Table I, patients 3 through 9). All of these patients had no clinical symptoms. No statistically significant predictors of femoral artery complications : rer? identified.

The incidence of femoral artery complications as determined by clinical criteria was $7 \%$. This incidence is consistent with previously published results. ${ }^{2}$ In this study, all clinically detected complications resolved immediately after catheter removal, with no long-term consequences. There are a few case reports of other complications after femoral artery cannulation, such as femoral artery thrombosis necessitating thrombectomy and causing tissue loss. ${ }^{2}$ No such complications occurred during this study.

It is well known that clinical criteria are insensitive in diagnosing femoral artery obstruction in children ${ }^{3-5}$ For this reason, we used ultrasonography to examine the femoral artery in children. We had found that $32 \%$ of infants undergoing cardiac catheterization had complete femoral artery obstruction, and many of these had no clinical signs or symptoms. ${ }^{3}$ We had also reported that $26 \%$ of a select group of symptom-free children who underwent transfemoral arterial balloon angioplasty or valvuloplasty had complete femoral artery obstruction. ${ }^{4}$ In the current study, $20 \%$ of patients had complete femoral artery obstruction and 3\% partial femoral artery obstruction diagnosed by ultrasonography after cannulation. The long-term significance of femoral artery obstruction in children without symptoms is unknown, and further studies are necessary.

The second purpose of this study was to determine predictors for femoral artery complications after cannulation. Previous authors ${ }^{2}$ have identified neonatal status, age younger than 5 years, and weight less than $10 \mathrm{~kg}$ as predictors of femoral artery complications, but none of these were so identified in this study.

Advantages of femoral artery catheters are the relative ease of insertion in infants and children, low incidence of complications, and pressure recordings that in certain clinical settings more accurately reflect true aortic pressure than do peripheral artery recordings. This last factor can be clinically significant when attempting to discontinue cardiopulmonary bypass after complex surgical repairs, when the proximal artery is crossclamped during the operative proce- dure (e.g., modified Blalock-Taussig shunt), or in situations in which peripheral vascular resistance is markedly increased (e.g., cardiogenic shock or infusion of vasoconstricting agents). Except in these clinical settings, our practice is to percutaneously cannulate the radial artery. If this is unsuccessful, the femoral artery is percutaneously cannulated. Finally, in some cases we prefer to proceed to radial artery cutdown rather than cannulating the femoral artery, as for patients in whom repeated cardiac catheterization through the femoral artery is anticipated (e.g., those with hypoplastic left heart syndrome).

The incidence of clinically detectable complications of femoral artery cannulation after perioperative monitoring in children was $7 \%$, and all resolved with catheter removal. Ultrasonography was used to detect asymptomatic femoral artery obstruction in $23 \%$ of patients. No statistically significant predictors for femoral artery complications were found.

We thank Daniel J. Kocis, Jr., PhD, for his assistance with the statistical analyses.

\section{REFERENCES}

1. Sellden H, Nilsson K, Larsson LE, Ekstrom-Jodal B. Radial arterial catheters in children and neonates: a prospective study. Crit Care Med 1987;15:1106-9.

2. Graves PW, Davis AL, Maggi JC, Nussbaum E. Femoral artery cannulation for monitoring in critically ill children: prospective study. Crit Care Med 1990;18:1363-6.

3. Kocis KC, Snider AR, Vermilion RP, Beekman RH. Two dimensional and Doppler ultrasonographic evaluation of femoral arteries in infants following cardiac catheterization using a sheathed or non sheathed arterial catheter. Am J Cardiol 1995;75:642-5.

4. Vermilion RP, Snider AR, Bengur AR, Beekman RH. Doppler evaluation of femoral arteries in children after aortic balloon valvuloplasty or coarctation balloon angioplasty. Pediatr Cardiol 1993;14:13-8.

5. Taylor LM, Troutman R, Feliciano P, Menashe V, Sunderland C, Porter JM. Late complications after femoral artery catheterization in children less than five years of age. $J$ Vase Surg 1990;11:297-306. 